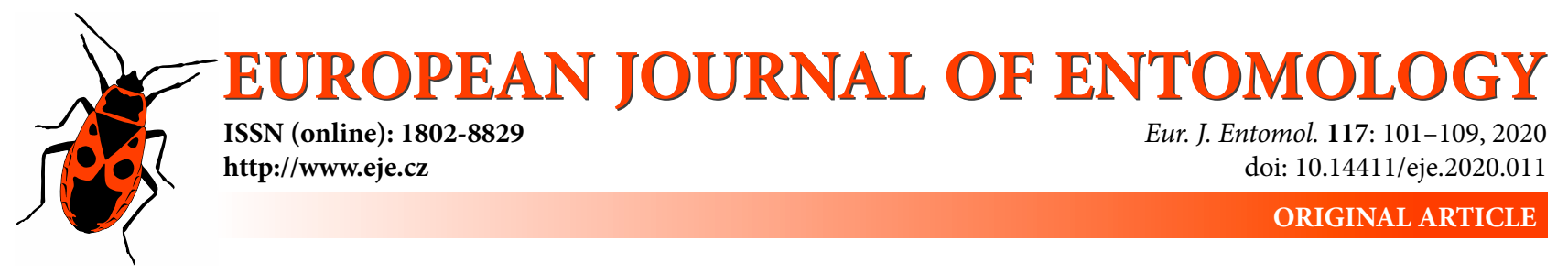

\title{
Volatile production differs between oak leaves infested by leaf-miner Phyllonorycter harrisella (Lepidoptera: Gracillariidae) and galler Neuroterus quercusbaccarum (Hymenoptera: Cynipidae)
}

\author{
FABIAN S. KLIMM ${ }^{1}$, AleXANder WEINHOLD ${ }^{2,3}$ and Martin VOLF W $^{3,4}$ \\ ${ }^{1}$ Institute of Ecology and Evolution, University of Jena, 07743 Jena, Thuringia, Germany; \\ e-mail: fabian.simon.klimm@uni-jena.de \\ 2 Institute of Biodiversity, University of Jena, 07743 Jena, Thuringia, Germany \\ ${ }^{3}$ German Centre for Integrative Biodiversity Research (iDiv) Halle-Jena-Leipzig, 04103 Leipzig, Saxony, Germany; \\ e-mails: alexander.weinhold@idiv.de, martin.volf@idiv.de \\ ${ }^{4}$ Biology Centre, Czech Academy of Sciences, Institute of Entomology, Branisovska 31, 37005 Ceske Budejovice, \\ Czech Republic; e-mail: volf@entu.cas.cz
}

Key words. Lepidoptera, Gracillariidae, Phyllonorycter harrisella, Hymenoptera, Cynipidae, Neuroterus quercusbaccarum, volatile organic compounds, indirect defence, methyl jasmonate, host manipulation, mine, gall, herbivory, oak, sesquiterpenes, farnesene, eucalyptol, $\beta$-bourbonene

\begin{abstract}
Plants defend themselves by producing various volatile organic compounds (VOCs) that have direct and indirect effects on insect herbivores. Their production is often specific to the plant and herbivore species involved, with some herbivores being able to manipulate their production. Here, we used passive volatile sampling using polydimethysiloxane (PDMS) tubing to compare VOCs produced by control, mined and galled oak leaves in the field. Leaves mined by a microlepidopteran leaf-miner (Phyllonorycter harrisella) produced a lower amount of two sesquiterpenes and an increased amount of eucalyptol. In contrast, leaves galled by the gall wasp (Neuroterus quercusbaccarum) did not produce a lower amount of any of the VOC measured when compared to the control. They produced a higher amount of farnesene, $\beta$-bourbonene and eucalyptol. Some of these VOC are known for their anti-herbivore function. In a second experiment, we treated the experimental leaves with the phytohormone methyl jasmonate (MeJA) to determine if leaf-miners or gallers reduced the overall inducibility of infested leaves. MeJA induced a sixteenfold increase in VOC production. However, there was no difference in VOC production of control, mined and galled leaves treated with MeJA. Our results show that up- and down-regulation of VOCs can vary among leaves infested by different herbivores. More experiments are needed to determine if this is due to manipulation by the herbivores themselves or due to a defensive response of the plant.
\end{abstract}

\section{INTRODUCTION}

With approximately 6.1 million estimated species, arthropods are a highly successful group (Hamilton et al., 2013). Their diversity is most commonly ascribed to the diversity of their feeding strategies, of which herbivory is the most widespread (Slansky \& Rodriguez, 1987). In response to herbivory, plants have developed various defensive strategies, including a huge variety of secondary metabolites with both direct and indirect effects on herbivores (Degen et al., 2004; Wink, 2006). Direct chemical defences are targeted directly at the herbivore, affecting its behaviour or physiology. On the other hand, indirect chemical defences, such as herbivore induced plant volatiles (HIPVs), attract the predators and parasitoids of the herbivore (Aljbory \& Chen, 2018). For example, blends of volatile organic compounds (VOCs) emitted by herbivore- damaged leaves stimulate parasitoid ovipositional probing behaviour (Dutton et al., 2000) or attract birds (Mäntylä et al., 2008; Amo et al., 2013).

HIPVs are highly specific to particular species of herbivores (Danner et al., 2018) and act by attracting predators or parasitoids, which makes them an efficient form of defence against a diverse set of arthropod herbivores (De Moraes et al., 1998; Turlings \& Erb, 2018). In response to the proliferation of plant defences, arthropod herbivores have evolved mechanisms like detoxification and sequestration (Heckel, 2014). Many guilds of arthropod herbivores, such as sap-suckers, leaf-chewers, leaf-miners or gallers, have even evolved an ability to manipulate plant metabolic pathways to their own advantage (Mapes \& Davies, 2001; Tooker \& De Moraes, 2011; Chung et al., 
2013; Savchenko et al., 2013; Giron et al., 2016; Zhang et al., 2016; Zhang, 2017).

In particular, gall-inducing arthropods are an excellent example of host manipulation. This group of herbivores is able to alter the metabolic pathways of the host and manipulate them to produce galls, which provide both shelter and highly nutritive food for the herbivore (Stone \& Schönrogge, 2003). In addition, gallers stimulate the indole-3-acetic acid (IAA) pathway in plants, which can result in the downregulation of both the salicylic acid (SA) and the jasmonic acid (JA) pathways, by their negative crosstalk (Tooker \& Helms, 2014). As a result, gallers not only manipulate the nutritive quality of plant tissues, but also downregulate defences of their hosts that depend on SA and JA pathways (Tooker et al., 2008; Hall et al., 2017). Many gallers are reported manipulating host VOCs (Tooker \& De Moraes, 2007; Tooker et al., 2008; TorresGurrola et al., 2011). The specific effects, however, seem to depend on the herbivore-plant system studied (Hall et al., 2017; Borges, 2018). In some cases, the synthesis of VOCs does not differ in galled and intact plants (Hall et al., 2017), whereas in other cases VOCs that attract natural enemies of gallers are downregulated in the abovementioned fashion (Tooker \& De Moraes, 2007).

Leaf-miners are another herbivore guild known to manipulate the nutritive value and defences of their hosts (Dutton et al., 2000; Vogler et al., 2010; Zhang et al., 2016; Zhang, 2017). Leaf-miners are known to maintain nutrient-rich green tissues in senescent and even fallen leaves, termed the green island phenotype (Giron et al., 2016). Leaf-miners induce cytokinins (CKs), phytohormones that regulate plant growth and affect senescence (Zhang et al., 2018). Recently, it was shown that a certain leaf-mining species (Borboryctis euryae: Gracillariidae) is able to actively induce callus proliferation (Guiguet et al., 2018). Consequently, such a manipulation can hamper direct and indirect chemical defences of the plant (Giron et al., 2007). In addition, leaf-miners are known to induce changes in the VOC profiles of plants (Johne et al., 2006; Vogler et al., 2010; De Backer et al., 2017). Detailed understanding of the manipulation of VOCs by leaf-miners is currently lacking, but downregulation of VOCs is recorded (Vogler et al., 2010; Zhang et al., 2016) and different mechanisms proposed (Zhang, 2017). For example, by interfering with CK production, leaf-miners may be able to disrupt synthesis of sesquiterpenes, as both supposedly originate from the mevalonate (MVA) pathway. In addition, they may affect HIPV synthesis by manipulating the JA-pathway (Zhang, 2017).

To test if VOC emissions from leaves infested by leafminers and gallers differ, we compared VOCs emitted by control, mined and galled leaves of Quercus robur. In addition, in a second experiment, we treated the experimental leaves with methyl jasmonate (MeJA), which is known to trigger strong VOC production (Rodriguez-Saona et al., 2001). We compared whether the inducibility of leaves infected by gallers and leaf-miners differed from the control. We expected: (i) VOC production would be reduced or un- changed in both galled and mined leaves in comparison to healthy leaves, and (ii) the inducibility of VOC production would be reduced in galled leaves as well as in mined leaves.

\section{METHODS}

\section{Experimental site and organisms}

We conducted the field part of this study from July $24^{\text {th }}$ to July $27^{\text {th }} 2018$ at a study site of Leipzig University, the Arboretum Großpösna $\left(51^{\circ} 40^{\prime} \mathrm{N}, 12^{\circ} 30^{\prime} \mathrm{E}\right)$.

We used Quercus robur as the host species for our experiment. Q. robur harbours a high diversity of gallers and leaf-miners. It is an ideal species for exploring responses to such herbivores. Oak VOCs include mainly monoterpenes, sesquiterpenes or fatty acid derivatives that can supposedly serve both as direct and indirect chemical defences (Pearse et al., 2013). We focused our observational study on a single mature $Q$. robur tree (diameter at breast height $=27.7 \mathrm{~cm}$ ). This design has limitations in terms of generalising our results. However, it excluded other potential sources of variation such as the genetic background of the host or environmental conditions.

We selected 10 healthy, 10 galled and 10 mined leaves on this tree. Average size of the selected leaves was $42.43 \mathrm{~cm}^{2} \pm$ 2.68. The selected leaves were $\mathrm{E}$ or SE oriented and ca 1.0-1.8 $\mathrm{m}$ above ground. All sampled leaves were mature and fully developed. The control leaves were undamaged by herbivores or pathogens and did not show any signs of mechanical damage. On the galled leaves there was an average of $32 \pm 6.32$ galls. The average area of a single gall was $0.0785 \mathrm{~cm}^{2} \pm 0.0064$. Leaf area covered by galls averaged $6.62 \% \pm 1.65$. In mined leaves there was an average of $1.8 \pm 0.25$ mines. The average mine area was $0.1081 \mathrm{~cm}^{2} \pm 0.0215$. Leaf area mined averaged $5.59 \% \pm 0.75$.

The leaf miner studied was Phyllonorycter harrisella (Linnaeus, 1761), the larvae of which feed exclusively on Quercus species. They go through three different developmental stages: an early serpentine phase, intermediate blotch phase and late tentiform phase. All selected mines were in the blotch phase.

The galler studied was Neuroterus quercusbaccarum (Linnaeus, 1758), which only galls oaks. N. quercusbaccarum has both agamic and bisexual generations. The agamic generation appears in spring. Unfertilized eggs are laid in the buds of Quercus leaves, where the larvae induce red, spherical galls. From these galls, the bigamic adults emerge in June, which lay fertilized eggs on the underside of oak leaves. The larvae induce flat, reddish disks, which were present when we conducted our experiment. All the galls were in a similar developmental stage.

We identified the gallers in the field based on gall morphology. The leaf-miner identity was confirmed by DNA barcoding using COI and standard primers and protocols (Folmer et al., 1994).

\section{VOC trapping}

We sampled oak VOCs by passive trapping with polydimethylsiloxane (PDMS) tubes following a modified protocol of that used by Kallenbach et al. (2015). This method was previously successfully used for sampling VOCs in the field (Nordström et al., 2017). It reliably captures monoterpenes and sesquiterpenes (Kallenbach et al., 2014), which are the main constituents of oak VOC blends (Pearse et al., 2013).

Using the PDMS tubes, we sampled VOCs from individual leaves. First, we attached two PMDS tubes (technical replicates) by wire to each leaf. We then enclosed individual leaves and the PDMS tubes in polyamide (PA) oven bags. We closed the bags as tight as possible without damaging the leaf. We sampled VOCs from the headspace for approximately $24 \mathrm{~h}$, then removed the 
tubes and brought them to the laboratory for further analysis. Hereafter we refer to this dataset as "pre-treatment".

After we sampled the VOCs for the first time, we treated the experimental leaves with MeJA that is commonly used to simulate herbivory and induce plant defences in a standard way (Degenhardt \& Lincoln, 2006). We treated the leaves by spraying them with a $20 \mathrm{mM}$ MeJA mixture $(20 \mathrm{mM}$ MeJA in $1 \% \mathrm{EtOH}$ and $0.1 \%$ Triton-X), following Mrazova \& Sam (2018) and Belhadj et al. (2006), who used MeJA concentrations of up to $15 \mathrm{mM}$ and 30 $\mathrm{mM}$, respectively, in their experiments on willows and grapevine. After approximately 90 min the plastic bags were closed again and VOCs were passively sampled for $24 \mathrm{~h}$ as described above. Hereafter we refer to this dataset as "post-treatment".

Once the sampling was finished, we harvested and photographed the leaves. The images were processed and analysed in imageJ (Abràmoff et al., 2004) to obtain the area of individual leaves and area occupied by herbivores.

\section{Chemical analysis}

We used gas chromatography to quantify the sampled VOCs. The PDMS tubes were analysed using a thermal desorption-gas chromatograph-mass spectrometer (TD-GC-MS) consisting of a thermodesorption unit (MARKES, Unity 2, Llantrisant, United Kingdom) equipped with an autosampler (MARKES, Ultra 50/50). PDMS tubes were transferred to empty stainless steel tubes (MARKES) and desorbed with helium as the carrier gas and a flow path temperature of $150^{\circ} \mathrm{C}$ using the following conditions: dry purge $5 \mathrm{~min}$ at $20 \mathrm{ml} / \mathrm{min}$, pre purge $2 \mathrm{~min}$ at $20 \mathrm{ml} / \mathrm{min}$, desorption $8 \mathrm{~min}$ at $280^{\circ} \mathrm{C}$ with $20 \mathrm{ml} / \mathrm{min}$, pre trap fire purge 1 min at $30 \mathrm{ml} / \mathrm{min}$, trap heated to $300^{\circ} \mathrm{C}$ and hold for $4 \mathrm{~min}$. The VOCs were separated on a gas chromatograph (Bruker, GC-456, Bremen, Germany) connected to a triple-quad mass spectrometer (Bruker, SCION) equipped with DB-WAX column: $(30 \mathrm{~m} \times 0.25$ $\mathrm{mm}$ inner diameter $\times 0.25$ um film thickness, Restek). The temperature program was: $60^{\circ} \mathrm{C}$ (hold $2 \mathrm{~min}$ ), $30^{\circ} \mathrm{C} / \mathrm{min}$ to $150^{\circ} \mathrm{C}$, $10^{\circ} \mathrm{C} / \mathrm{min}$ to $200^{\circ} \mathrm{C}$ and $30^{\circ} \mathrm{C} / \mathrm{min}$ to $230^{\circ} \mathrm{C}$ (hold $5 \mathrm{~min}$ ). Helium was used as the carrier gas at a constant flow rate of $1 \mathrm{ml} /$ mi. MS conditions were set at a $40^{\circ} \mathrm{C}$ manifold, $240^{\circ} \mathrm{C}$ transfer line and $220^{\circ} \mathrm{C}$ for the ion source. The scan-range was $33-500$ $\mathrm{m} / \mathrm{z}$ for a full scan and scan-time was $250 \mathrm{~ms}$. We selected the most prominent peaks in the chromatograms (signal to noise ratio $>10$ ). Peaks that were also present in air blanks were regarded as systemic contamination and were excluded from further analysis. VOCs were tentatively identified by comparison with the NIST database and comparison with retention indices in the literature. The peak areas of these compounds were calculated using the Bruker Workstation software (v8.0.1).

\section{Statistical analysis}

VOC concentration was standardised for leaf area by calculating VOC production per $\mathrm{cm}^{2}$ to account for variation in leaf size. First, we analysed if the total production of VOCs, their diversity (measured as Shannon-Index) and production of individual VOCs differed between control, mined and galled leaves using ANOVA. Total VOC production (summarised as the total peak area) and the area of peaks of individual compounds were log transformed. When a significant effect of herbivore infestation on the production of VOCs was recorded, we performed a post-hoc Tukey HSD test to compare the individual treatments. Pre- and post-treatment samples were analysed separately. The analyses were performed in $\mathrm{R}$ ( $\mathrm{R}$ core team, Version 3.4.3, 2017).

Second, we compared the overall VOC profiles of control, mined and galled leaves using multivariate statistical methods. Areas of peaks of individual compounds were log transformed and used as response variables in the analyses. We visualised the differences in VOC production of individual leaves using Principal Component Analysis (PCA). Then we analysed the effect of herbivore infestation using Redundancy Analysis (RDA). We used herbivore presence/absence as explanatory variables in the first analysis. As there was some variation in the area occupied by the herbivores, we then ran a second analysis using the quantitative data on the leaf area affected by the herbivores to confirm the results. The significance of the constrained axes was tested using Monte-Carlo test with 9999 permutations. Pre- and post-treatment samples were analysed separately. All multivariate analyses were conducted in CANOCO 5 (ter Braak \& Šmilauer, 2012).

Finally, we tested if the VOC production increased after the MeJA treatment and if the response in terms of the total production of VOCs and production of individual VOCs differed between control, mined and galled leaves using repeated measures ANOVA. The total VOC production (summarised as the total peak area) and area of peaks of individual compounds were log transformed. MeJA treatment and herbivore infestation were used as explanatory variables. Leaf identity was used as a random factor. The analyses were performed in $\mathrm{R}$ ( $\mathrm{R}$ core team, Version $3.4 .3,2017)$. Only the leaves for which the data from both preand the post-treatment were available, were included in this analysis. Therefore, the number of galled leaves in this analysis was reduced to eight (one leaf had to be replaced before the induction experiment and one died due to mechanical damage during the induction experiment).

\section{RESULTS}

In total, we quantified 36 VOC compounds produced by the leaves (Table S1). Herbivore infestation did not have a significant effect on the total production of VOCs or their diversity in the pre- or post-treatments (Table 1). However, herbivore infestation affected production of five VOCs significantly when we analysed the production of individual compounds in the pre-treatment dataset. The production of eucalyptol (1-,8-cineol) was upregulated in galled and mined leaves (not detected in control leaves; peak area $122.89 \pm 41.00$ in mined leaves and $135.50 \pm 64.75$ in galled leaves; $\left.\mathrm{F}_{(2,27)}=5.506, \mathrm{p}=0.010\right)$. The production of $\beta$-bourbonene and farnesene was upregulated in galled leaves only. The production of $\beta$-bourbonene was $3 \times$ higher in galled leaves when compared to control leaves $(23,486.71 \pm 4,294.22$ in galled leaves vs. 7,874.61 \pm $2,226.76$ in the control; $\left.\mathrm{F}_{(2,27)}=4.795, \mathrm{p}=0.017\right)$. The production of farnesene was $4.2 \times$ higher compared to the control $(94,646.76 \pm 37,688.91$ in galled leaves vs. $22,451.98$ $\pm 9,359.14$ in the control; $\left.\mathrm{F}_{(2,27)}=5.906, \mathrm{p}=0.015\right)$. Mined leaves did not significantly differ from control leaves in terms of $\beta$-bourbonene or farnesene $(13,010.74 \pm 4478.86$ for $\beta$-bourbonene, 17,593.86 $\pm 5,801.01$ for farnesene). The production of unknown sesquiterpenes 1 and 2 was

Table 1. Differences in total volatile production (in terms of the total peak area per $\mathrm{cm}^{2}$ of the leaf sampled) and Shannon-Diversity before ("pre-treatment") and after the MeJA-treatment ("post-treatment") as measured using a one-way ANOVA.

\begin{tabular}{lccc}
\hline Measure & Treatment & $\mathrm{F}_{(2,27)}$ & $\mathrm{p}$ \\
\hline \multirow{2}{*}{ Total VOC production } & pre & 2.522 & 0.099 \\
& post & 1.793 & 0.186 \\
\hline \multirow{2}{*}{ Shannon-Diversity } & pre & 0.290 & 0.751 \\
& post & 0.473 & 0.629 \\
\hline
\end{tabular}




\section{Pre-treatment}
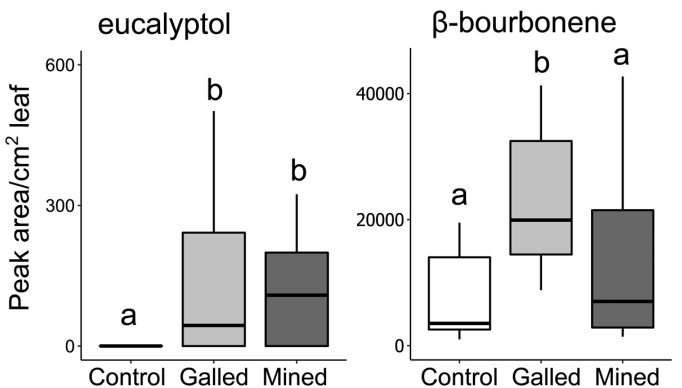

un. sesquiterpene 1

farnesene
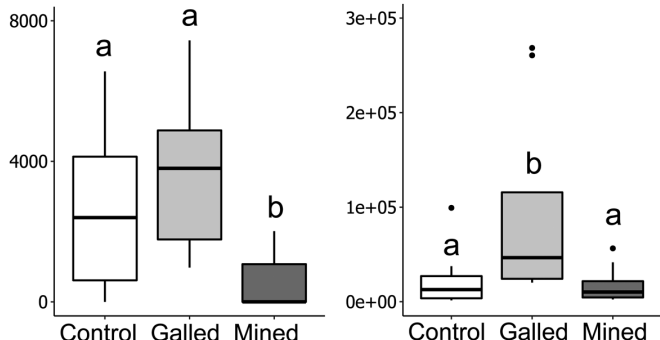

\section{Post-treatment}
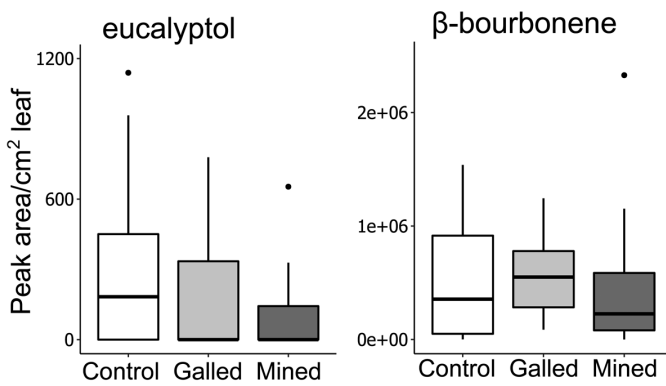

un. sesquiterpene 1
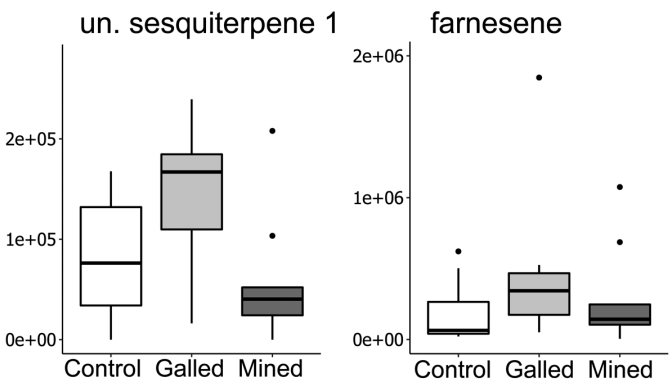

un. sesquiterpene 2

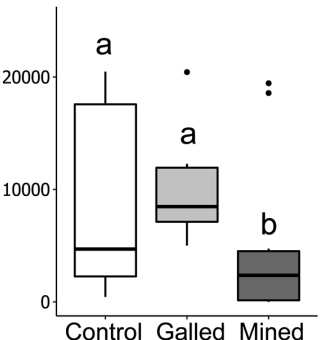

un. sesquiterpene 2

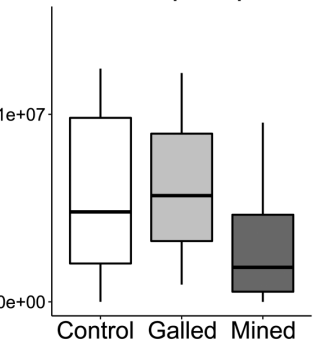

Fig. 1. Comparison of peak areas (standardised per $\mathrm{cm}^{2}$ of leaf area; $n=10$ for mined leaves and control, $n=8$ for galled leaves) of compounds significantly up- or downregulated in the galled and mined leaves in pre-treatment (above) and post-treatment (below) as identified by ANOVA and Tukey HSD tests. Boxes are quartiles 2 and 3, bars IQR 1.5, thick line the median. Significant differences between control, galled and mined leaves identified by post-hoc tests are indicated by lowercase letters.

A



$\infty$

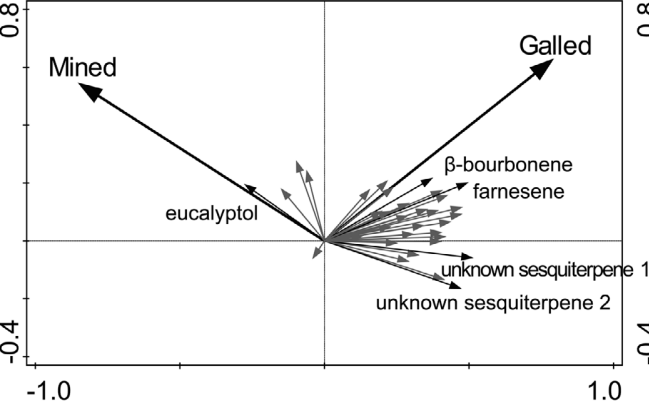

B

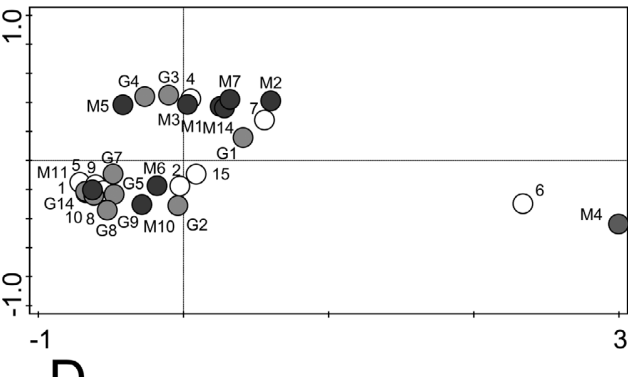

D

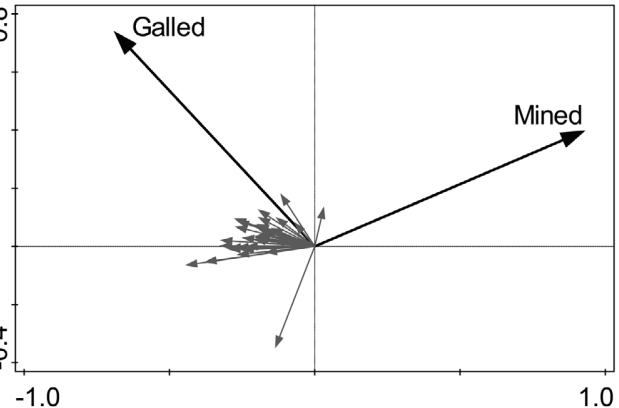

Fig. 2. Results of the PCA (above) and the RDA (below) of the pre-treatment (left) and post-treatment (right). A - variability in the volatile profiles emitted by the control, mined and galled leaves in the pre-treatment phase. First two unconstrained axes account for $51.78 \%$ of the variation. B - variability in volatile profiles emitted in the post-treatment phase. First two unconstrained axes account for $77.90 \%$ of the variation. $\mathrm{C}$ - the effects of herbivore infestation on the volatile profiles emitted by the control, mined and galled leaves in the pre-treatment phase. The constrained axes account for $14.1 \%$ of the total variation (pseudo- $F=2.2, p=0.0128$ ). Compounds that showed significant individual trends are in black and named. All other compounds are in grey. D - the effects of herbivore infestation on the volatile profiles emitted by the control, mined and galled leaves in the post-treatment phase. The constrained axes account for $6.9 \%$ of the total variation (pseudo-F $=1.2, p=0.3047$ ). 
downregulated in mined leaves $(530.03 \pm 237.77$ in mined leaves vs. $2,556.28 \pm 746.90$ in control, $\mathrm{F}_{(2,27)}=7.934, \mathrm{p}$ $=0.002$, for unknown sesquiterpene 1 ; and $5,185.83 \pm$ $2,363.90$ in mined leaves vs. 8,877.92 $\pm 2,587.23$ in control, $\mathrm{F}_{(2,27)}=4.099, \mathrm{p}=0.042$, for unknown sesquiterpene 2 ). Galled leaves did not significantly differ in the production of these two compounds $(3,701.44 \pm 772.11$ for unknown sesquiterpene 1 and 9,983.86 $\pm 1,746.14$ for unknown sesquiterpene 2; Fig. 1 above). No individual compound showed a significant response to herbivore infestation in post-treatment; Fig. 1 below).

The results of multivariate analyses were broadly consistent with the results of the ANOVA. The PCA for pretreatment samples showed high variability in VOC profiles among mined leaves (Fig. 2A). Galled leaves had more uniform VOC profiles, but still did not form a very clearly defined cluster. There were no clearly defined clusters in the PCA analysis of post-treatment samples (Fig. 2B). The RDA revealed that the herbivore infestation accounted for $14.1 \%$ of the total variation in pre-treatment samples (pseudo-F = 2.2, $\mathrm{p}=0.0128$; Fig. 2C). After treatment with MeJA, the significant effect disappeared (pseudo-F $=1.2, p$ $=0.3047$; Fig. 2D). The results remained largely unchanged when the quantitative data on the area occupied by the galls and mines of the herbivores were used. The herbivore infestation accounted for $12.6 \%$ of the total variation in pre-treatment samples ( $\mathrm{pseudo-F}=2.2, \mathrm{p}=0.0318$ ). After treatment with MeJA, the effect was no longer significant (pseudo-F $=1.0, \mathrm{p}=0.4019$ ).

The total VOC concentration increased sixteen-fold after treatment with MeJA (mean total peak area in pre-treatment $809,662.21$ vs. $133,314,94.40$ in post-treatment, $\mathrm{F}_{(1,53)}$ $=90.063, \mathrm{p}<0.001)$. Regarding individual compounds, all of them except three, one of which was eucalyptol $\left(\mathrm{F}_{(1,49)}=\right.$ $0.519, \mathrm{p}=0.4746)$, were emitted in a significantly higher concentration after treatment with MeJA. There was no significant interaction between the treatment and the herbivore infestation on the total production of VOCs $\left(\mathrm{F}_{(2,49)}=\right.$ $0.086, \mathrm{p}=0.9173$ ) or production of individual compounds.

\section{DISCUSSION}

We examined the effects of infestations of a galler and leaf-miner on the production of leaf VOCs in Quercus robur. We did not find a decrease in total production or diversity of VOCs emitted by infested leaves. Neither did we detect any downregulation of individual terpenoid VOCs in galled leaves as reported in some previous studies (Tooker \& De Moraes, 2007; Torres-Gurrola et al., 2011; Jiang et al., 2018). However, we recorded that the production of two unidentified sesquiterpenes was downregulated only in mined leaves. In addition, three compounds were upregulated in both galled and mined leaves or only in galled leaves. These results confirm findings of previous studies and illustrate that VOC production can vary between leaves infested by different herbivores (Vogler et al., 2010; Clavijo McCormick et al., 2014; Jiang et al., 2018).

Leaf-miners are able to alter metabolic pathways of their hosts and modulate the production of major phytohormones
(Body et al., 2013; Zhang et al., 2016). This includes changes in biosynthesis of jasmonic acid, salicylic acid, abscisic acid or cytokinins (Giron et al., 2016; Zhang, 2017). Such changes can positively affect the nutritive value of the tissue the leaf-miner feeds on and can hamper the direct and indirect chemical defences of the host (Zhang et al., 2016; Guiguet et al., 2018). For example, apple plants infested with Phyllonorycter blancardella emit less sesquiterpenes than healthy ones (Vogler et al., 2010). Potentially, this could benefit the miner as some sesquiterpenes can attract parasitoids or repel ovipositing females when produced in larger quantities in that system (Dorn \& Hern, 1999; Vogler et al., 2010). Here we recorded a similar trend as oak leaves infested with $P$. harrisella produced a lower amount of two unknown sesquiterpenes. Although this may suggest a possible manipulation of oak sesquiterpenes by $P$. harrisella, it is not possible conclude whether the lower production of these VOCs is a by-product of induced changes in metabolic pathways or whether their downregulation possibly benefits the leaf-miner. Identifying the precise structures and conducting manipulative experiments on the bioactivity of these compounds would be needed to confirm this.

None of VOCs were produced in lower amounts by the leaves infested with the studied gallers. Gallers are known for their ability to manipulate their hosts (Giron et al., 2016). Such manipulation can also involve downregulating the production of VOCs in some cases, as reported for the dipteran Mayetiola destructor (Tooker \& De Moraes, 2007) and the hemipteran Trioza anceps (McKinnon et al., 1999; Tooker \& De Moraes, 2007; Torres-Gurrola et al., 2011; Jiang et al., 2018). However, this does not always seem to be the case. In their review, Hall et al. (2017) show that galling insects downregulate mainly the direct chemical defences of their hosts, while the production of many VOCs does not differ between galled and control plants. They attribute this to the different function of direct and indirect chemical defences. Downregulating chemical defences with direct negative effects is usually beneficial for the galler (Sarmento et al., 2011). On the other hand, maintaining VOC constitutive levels may be a more beneficial strategy than their downregulation as this could mask the presence of the galling insect from its natural enemies (Hall et al., 2017).

Infestation with the galling insect, and to a lesser extent the leaf-miner, also led to an upregulation of several VOCs (eucalyptol, $\beta$-bourbonene and farnesene) and to VOC profiles that significantly differed from that of the control leaves. This is similar to the findings of Jiang et al. (2018), who report an increase in VOC production by Quercus robur leaves infested with the gall wasps Cynips spp. and Neuroterus albipes. Compounds upregulated in the leaves infested by galling and mining insects differed slightly in our study. Eucalyptol was upregulated in both mined and galled leaves. Eucalyptol is known for its insect-repellent (Edwards et al., 1993; Sfara et al., 2009) and insecticide effects (Sabraoui et al., 2016). Its production is often stimulated by herbivory (Torres-Gurrola et al., 2011; Santos et al., 2016). On the other hand, $\beta$-bourbonene and farnesene 
were upregulated only in galled leaves. Farnesenes are present in VOC blends emitted by a wide range of species of plants in response to herbivory (Dorn \& Hern, 1999; Kigathi et al., 2009; Allmann \& Baldwin, 2010; Pierre et al., 2011). They seem to act as both direct defences, by repelling herbivores, and as indirect defences, in attracting their natural enemies (De Moraes et al., 1998; Wei \& Kang, 2006). Vogler et al. (2010) record a lower production of farnesenes in miner-infested leaves of apple plants. Although we did not record a similar trend, it is interesting that while the leaves galled by the galling insect produced a higher amount of farnesene those infested by miners did not differ in farnesene production from the control.

The compound $\beta$-bourbonene was previously detected in VOC bouquets of Quercus robur (Ghirardo et al., 2012), where it is upregulated in response to herbivory by the leaf-rolling microlepidopteran Tortrix viridana. Its upregulation is also reported in other plant species, typically in response to damage by chewing insect herbivores (Mäntylä et al., 2008; Gossner et al., 2014). Together with our results, this indicates that the production of $\beta$-bourbonene can be upregulated in leaves attacked by various herbivores, or by leaf-chewing and galling herbivores. Although some results indicate that $\beta$-bourbonene might be involved in attracting predators (Mäntylä et al., 2008), more information on its specific bioactivity is needed to fully explore its role. This is also the case of several of the compounds mentioned above. Yet, having information on the bioactivity of VOCs is crucial for interpreting similar results. This is because upregulation of various metabolites and pathways can have differential effects on herbivores. For example, the Colorado potato beetle (Leptinotarsa decemlineata) and its symbiotic bacteria elicit the SA pathway and its dependent defences while supressing the induction of JA dependent defences by SA and JA negative crosstalk (Chung et al., 2013). In turn, herbivory leads to upregulation of plant defences but not the ones efficient against the respective herbivore, which benefits the beetle.

We found no difference in VOC production between control, mined and galled leaves once they were treated with MeJA. This was probably due to the high concentration of MeJA we used and its strong effect, which may have saturated the plant's response. We were thus unable to address our second hypothesis that the inducibility will differ between mined, galled and control leaves. MeJA is commonly used in ecological studies as it triggers a massive and unspecific response in VOC production (Franceschi et al., 2002; Kost \& Heil, 2008; Mäntylä et al., 2014). High concentrations of MeJA are used when assessing general patterns such as the attraction of predators by plant VOCs (Belhadj et al., 2006; Mrazova \& Sam, 2018). However, the effects of highly concentrated MeJA can mask responses to naturally occurring herbivory as illustrated by our study. Using lower concentrations of MeJA, such as in Rigsby et al. (2019), would be advisable for experiments similar to the one we carried out. Alternatively, using real herbivores, such as caterpillars, could be an even better way to investigate the changes in VOC inducibility under natural conditions (Peñaflor et al., 2017).

More surveys are needed to explore the diversity of plant VOCs, their responses to herbivory under natural conditions and their bioactivity. One of the main limitations of our study is the small sample size. Methods of passive VOC sampling should facilitate a significant increase in sample size in future studies. As demonstrated by Kallenbach et al. (2014) and Chalal et al. (2015), PDMS tubes are a labour- and cost-efficient as well as easy-to-handle method of passive sampling of VOCs. We showed that this method is able to detect differences in VOC production between leaves infested by different herbivores. In combination with recent advances in the -omic approaches, mass spectrometry and gas chromatography (Wu et al., 2013; Dyer et al., 2018), such field surveys supported by manipulative experiments are likely to greatly contribute to our comprehension of complex trophic interactions between plants and insects.

ACKNOWLEDGEMENTS. We would like to thank R. Sontowski, who helped with the barcoding. MV acknowledges funding by the Alexander von Humboldt Foundation and Federal Ministry for Education and Research Ref.3.3-CZE-1192673-HFST-P. AW and MV gratefully acknowledge the support of the German Centre for Integrative Biodiversity Research (iDiv) Halle-JenaLeipzig funded by the German Research Foundation (FZT 118).

\section{REFERENCES}

Abràmoff M.D., Magalhães P.J. \& Ram S.J. 2004: Image processing with ImageJ. — Biophotonics Int. 11: 36-42.

AlJBory Z. \& CHEN M.-S. 2018: Indirect plant defense against insect herbivores: a review. - Insect Sci. 25: 2-23.

AllmanN S. \& BALDWIN I.T. 2010: Insects betray themselves in nature to predators by rapid isomerization of green leaf volatiles. - Science (New York) 329: 1075-1078.

Amo L., Jansen J.J., van Dam N.M., Dicke M. \& Visser M.E. 2013: Birds exploit herbivore-induced plant volatiles to locate herbivorous prey. — Ecol. Lett. 16: 1348-1355.

Belhadj A., Saigne C., Telef N., Cluzet S., Bouscaut J., CoRio-Costet M.-F. \& Mérillon J.-M. 2006: Methyl jasmonate induces defense responses in grapevine and triggers protection against Erysiphe necator. - J. Agric. Food Chem. 54: 9119-9125.

Body M., Kaiser W., Dubreuil G., Casas J. \& Giron D. 2013: Leaf-miners co-opt microorganisms to enhance their nutritional environment. - J. Chem. Ecol. 39: 969-977.

Borges R.M. 2018: The galling truth: Limited knowledge of gall-associated volatiles in multitrophic interactions. - Front. Plant Sci. 9: 1139, 8 pp.

Chalal M., Winkler J.B., Gourrat K., Trouvelot S., Adrian M., Schnitzler J.-P., Jamois F. \& Daire X. 2015: Sesquiterpene volatile organic compounds (VOCs) are markers of elicitation by sulfated laminarine in grapevine. - Front. Plant Sci. 6: 350,9 pp.

CHor H.-S. 2003: Character impact odorants of citrus hallabong $[(C$. unshiu Marcov $\times C$. sinensis Osbeck $) \times C$. reticulata Blanco] cold-pressed peel oil. — J. Agric. Food Chem. 51: 2687-2692.

Chung T.Y., Eiserich J.P. \& Shibamoto T. 1993: Volatile compounds isolated from edible Korean chamchwi (Aster scaber Thunb). — J. Agric. Food Chem. 41: 1693-1697. 
Chung S.H., Rosa C., Scully E.D., Peiffer M., Tooker J.F., HooVer K., Luthe D.S. \& Felton G.W. 2013: Herbivore exploits orally secreted bacteria to suppress plant defenses. - Proc. Nat. Acad. Sci. U.S.A. 110: 15728-15733.

Clavijo McCormick A., Irmisch S., Reinecke A., Boeckler G.A., Veit D., Reichelt M., Hansson B.S., Gershenzon J., Köllner T.G. \& UNSICKER S.B. 2014: Herbivore-induced volatile emission in black poplar: regulation and role in attracting herbivore enemies. - Plant Cell Environ. 37: 1909-1923.

Danner H., Desurmont G.A., Cristescu S.M. \& van Dam N.M. 2018: Herbivore-induced plant volatiles accurately predict history of coexistence, diet breadth, and feeding mode of herbivores. - New Phytol. 220: 726-738.

De Backer L., Bawin T., Schott M., Gillard L., Markó I.E., FrANCIS F. \& VERHEGGEN F. 2017: Betraying its presence: identification of the chemical signal released by Tuta absoluta -infested tomato plants that guide generalist predators toward their prey. - Arthr.-Plant Interact. 11: 111-120.

De Moraes C.M., Lewis W.J., Paré P.W., Alborn H.T. \& TumLINSON J.H. 1998: Herbivore-infested plants selectively attract parasitoids. - Nature 393: 570-573.

Degen T., Dillmann C., Marion-Poll F. \& Turlings T.C.J. 2004: High genetic variability of herbivore-induced volatile emission within a broad range of maize inbred lines. - Plant Physiol. 135: 1928-1938.

Degenhardt D.C. \& Lincoln D.E. 2006: Volatile emissions from an odorous plant in response to herbivory and methyl jasmonate exposure. - J. Chem. Ecol. 32: 725-743.

Dorn S. \& Hern A. 1999: Herbivore-induced volatiles in the apple orchard ecosystem. - IOBC WPRS Bull. 22(9): 67-72.

DutTon A., Mattiacci L. \& Dorn S. 2000: Plant-derived semiochemicals as contact host location stimuli for a parasitoid of leafminers. - J. Chem. Ecol. 26: 2259-2273.

Dyer L.A., Philibin C.S., Ochsenrider K.M., Richards L.A., Massad T.J., Smilanich A.M., Forister M.L., Parchmann T.L., Galland L.M., Hurtado P.J., Espeset A.E., Glassmire A.E., Harrison J.G., Mo C., Yoon S.A., Pardikes N.A., Muchoney N.D., Jahner J.P., Slinn H.L., Shelef O., Dodson C.D., Kato M.J., YAMAGUCHI L.F. \& JEFFREY C.F. 2018: Modern approaches to study plant-insect interactions in chemical ecology. Nature Rev. Chem. 2: 50-64.

Edwards P.B., Wanjura W.J. \& Brown W.V. 1993: Selective herbivory by Christmas beetles in response to intraspecific variation in Eucalyptus terpenoids. - Oecologia 95: 551-557.

Ferreira V., Aznar M., Lopez R. \& Cacho J. 2001: Quantitative gas chromatography-olfactometry carried out at different dilutions of an extract. Key differences in the odor profiles of four high-quality Spanish aged red wines. - J. Agric. Food Chem. 49: 4818-4824.

Folmer O., Black M., Hoeh W., Lutz R. \& VRijenhoek R. 1994 DNA primers for amplification of mitochondrial cytochrome. - Mol. Marine Biol. Biotechnol. 3: 294-299.

Franceschi V.R., Krekling T. \& Christiansen E. 2002: Application of methyl jasmonate on Picea abies (Pinaceae) stems induces defense-related responses in phloem and xylem. - Am. J. Bot. 89: 578-586.

Ghirardo A., Heller W., Fladung M., Schnitzler J.-P. \& Schroeder H. 2012: Function of defensive volatiles in pedunculate oak (Quercus robur) is tricked by the moth Tortrix viridana. - Plant Cell Environ. 35: 2192-2207.

Giron D., Kaiser W., Imbault N. \& Casas J. 2007: Cytokininmediated leaf manipulation by a leafminer caterpillar. - Biology Lett. 3: 340-343.

Giron D., Huguet E., Stone G.N. \& Body M. 2016: Insect-induced effects on plants and possible effectors used by galling and leaf-mining insects to manipulate their host-plant. - J. Insect Physiol. 84: 70-89.

Gossner M.M., Weisser W.W., Gershenzon J. \& Unsicker S.B. 2014: Insect attraction to herbivore-induced beech volatiles under different forest management regimes. - Oecologia 176: 569-580.

Guiguet A., Hamatani A., Amano T., Takeda S., Lopez-VaAmonde C., Giron D. \& Ohshima I. 2018: Inside the horn of plenty: Leaf-mining micromoth manipulates its host plant to obtain unending food provisioning. - PLOS ONE 13(12): e0209485, $15 \mathrm{pp}$.

Hall C.R., Carroll A.R. \& Kitching R.L. 2017: A meta-analysis of the effects of galling insects on host plant secondary metabolites. - Arthr.-Plant Interact. 11: 463-473.

Hamilton A.J., Novotný V., Waters E.K., Basset Y., BenKe K.K., Grimbacher P.S., Miller S.E., Samuelson G.A., Weiblen G.D. \& YEN J.D.L. 2013: Estimating global arthropod species richness: refining probabilistic models using probability bounds analysis. - Oecologia 171: 357-365.

HECKEL D.G. 2014: Insect detoxification and sequestration strategies. In Voelckel C. \& Jander G. (eds): Annual Plant Reviews: Plant Insect Interactions. Wiley-Blackwell, Chichester, pp. 77-114.

JiAng Y., Veromann-JÜrgenson L.-L., Ye J. \& NiInEMEts Ü. 2018: Oak gall wasp infections of Quercus robur leaves lead to profound modifications in foliage photosynthetic and volatile emission characteristics. - Plant Cell Environ. 41: 160-175.

Johne A.B., Weissbecker B. \& Schütz S. 2006: Volatile emissions from Aesculus hippocastanum induced by mining of larval stages of Cameraria ohridella influence oviposition by conspecific females. - J. Chem. Ecol. 32: 2303-2319.

Kallenbach M., OH Y., Eilers E.J., Veit D., Baldwin I.T. \& SchuMAN M.C. 2014: A robust, simple, high-throughput technique for time-resolved plant volatile analysis in field experiments. - Plant J. Cell Mol. Biol. 78: 1060-1072.

Kallenbach M., Veit D., Eilers E.J. \& Schuman M.C. 2015: Application of silicone tubing for robust, simple, high-throughput, and time-resolved analysis of plant volatiles in field experiments. - Bio Protoc. 5(3): 12 pp.

Kigathi R.N., Unsicker S.B., Reichelt M., Kesselmeier J., GerSHENZON J. \& WEISSER W.W. 2009: Emission of volatile organic compounds after herbivory from Trifolium pratense (L.) under laboratory and field conditions. - J. Chem. Ecol. 35: 13351348.

Kost C. \& Heil M. 2008: The defensive role of volatile emission and extrafloral nectar secretion for lima bean in nature. $-J$. Chem. Ecol. 34: 2-13.

Mäntylä E., Alessio G.A., Blande J.D., Heijari J., Holopainen J.K., Laaksonen T., Pirrtola P. \& Klemola T. 2008: From plants to birds: higher avian predation rates in trees responding to insect herbivory. - PLOS ONE 3(7): e2832, 8 pp

Mäntylä E., Blande J.D. \& Klemola T. 2014: Does application of methyl jasmonate to birch mimic herbivory and attract insectivorous birds in nature? - Arthr.-Plant Interact. 8: 143-153.

MAPES C.C. \& DAVIES P.J. 2001: Cytokinins in the ball gall of Solidago altissima and in the gall forming larvae of Eurosta solidaginis. - New Phytol. 151: 203-212.

MCKINNON M.L., Quiring D.T. \& BAUCE E. 1999: Influence of tree growth rate, shoot size and foliar chemistry on the abundance and performance of a galling adelgid. - Funct. Ecol. 13: 859-867.

Mrazova A. \& SAm K. 2018: Application of methyl jasmonate to grey willow (Salix cinerea) attracts insectivorous birds in nature. - Arthr.-Plant Interact. 12: 1-8. 
NIST 2011: NIST Standard Reference Database 1A v17. URL: https://www.nist.gov/srd/nist-standard-reference-database-1av17.

Nordström K., Dahlbom J., Pragadheesh V.S., Ghosh S., Olsson A., Dyakova O., Suresh S.K. \& Olsson S.B. 2017: In situ modeling of multimodal floral cues attracting wild pollinators across environments. - Proc. Nat. Acad. Sci. U.S.A. 114: $13218-13223$.

Pearse I.S., Gee W.S. \& Beck J.J. 2013: Headspace volatiles from 52 oak species advertise induction, species identity, and evolution, but not defense. - J. Chem. Ecol. 39: 90-100.

Peñaflor M.F.G.V., Gonçalves F.G., Colepicolo C., Sanches P.A. \& Bento J.M.S. 2017: Effects of single and multiple herbivory by host and non-host caterpillars on the attractiveness of herbivore-induced volatiles of sugarcane to the generalist parasitoid Cotesia flavipes. — Entomol. Exp. Appl. 165: 83-93.

Pierre P.S., Jansen J.J., HordiJK C.A., van Dam N.M., Cortesero A.-M. \& Dugravot S. 2011: Differences in volatile profiles of turnip plants subjected to single and dual herbivory above-and belowground. - J. Chem. Ecol. 37: 368-377.

Rigsby C.M., Shoemaker E.E., Mallinger M.M., Orians C.M \& Preisser E.L. 2019: Conifer responses to a stylet-feeding invasive herbivore and induction with methyl jasmonate: impact on the expression of induced defences and a native folivore. Agric. For. Entomol. 21: 227-234.

Rodriguez-Saona C., Crafts-Brandner S.J., Paré P.W. \& HenNEBERRY T.J. 2001: Exogenous methyl jasmonate induces volatile emissions in cotton plants. - J. Chem. Ecol. 27: 679-695.

Sabraoui A., Bouhssini M.E.L., Lhaloui S., Boulmatat R. \& Bouchelta A. 2016: Effet insecticide des huiles essentielles sur la mineuse de pois chiche, Liriomyza cicerina R. - Rev. Maroc. Prot. Plantes 9: 39-46.

Santos S.A.P., Mota L., Malheiro R., Silva F., Campos M., Pinho P.G. DE \& Pereira J.A. 2016: Changes in volatile compounds of Dittrichia viscosa caused by the attack of the gall-forming dipteran Myopites stylatus. — Indust. Crops Prod. 87: 71-77.

Sarmento R.A., Lemos F., Bleeker P.M., Schuurink R.C., Pallini A., Oliveira M.G.A., Lima E.R., Kant M., Sabelis M.W. \& JANSSEN A. 2011: A herbivore that manipulates plant defence. - Ecol. Lett. 14: 229-236.

Savchenko T., Pearse I.S., Ignatia L., Karban R. \& Dehesh K. 2013: Insect herbivores selectively suppress the HPL branch of the oxylipin pathway in host plants. - Plant J. 73: 653-662.

Sfara V., Zerba E.N. \& Alzogaray R.A. 2009: Fumigant insecticidal activity and repellent effect of five essential oils and seven monoterpenes on first-instar nymphs of Rhodnius prolixus. - J. Med. Entomol. 46: 511-515.

Slansky F. \& Rodriguez J.G. 1987: Nutritional Ecology of Insects, Mites, Spiders, and Related Invertebrates. Wiley, New York, $1016 \mathrm{pp}$.

Stone G.N. \& SchönRogge K. 2003: The adaptive significance of insect gall morphology. — Trends Ecol. Evol. 18: 512-522.

Sylvestre M., Longtin A.P.A. \& Legault J. 2007: Volatile leaf contituents and anticancer activity of Bursera simaruba (L.) Sarg. essential oil. - Nat. Prod. Commun. 2: 1273-1276.

TER BraAk C.J.F. \& Šmilauer P. 2012: Canoco Reference Manual and User's Guide: Software for Ordination, Version 5.0. Microcomputer Power.
ToOKer J.F. \& De Moraes C.M. 2007: Feeding by hessian fly [Mayetiola destructor (Say)] larvae does not induce plant indirect defences. - Ecol. Entomol. 32: 153-161.

TOOKer J.F. \& De Moraes C.M. 2011: Feeding by a gall-inducing caterpillar species alters levels of indole-3-acetic and abscisic acid in Solidago altissima (Asteraceae) stems. - Arthr.-Plant Interact. 5: 115-124.

ToOKer J.F. \& Helms A.M. 2014: Phytohormone dynamics associated with gall insects, and their potential role in the evolution of the gall-inducing habit. - J. Chem. Ecol. 40: 742-753.

Tooker J.F., Rohr J.R., Abrahamson W.G. \& Moraes C.M.D. 2008: Gall insects can avoid and alter indirect plant defenses. - New Phytol. 178: 657-671.

Torres-Gurrola G., Delgado-Lamas G. \& Espinosa-García F.J. 2011: The foliar chemical profile of criollo avocado, Persea americana var. drymifolia (Lauraceae), and its relationship with the incidence of a gall-forming insect, Trioza anceps (Triozidae). - Biochem. Syst. Ecol. 39: 102-111.

TurLings T.C.J. \& ERB M. 2018: Tritrophic interactions mediated by herbivore-induced plant volatiles: Mechanisms, ecological relevance, and application potential. - Annu. Rev. Entomol. 63: $433-452$.

Vogler U., Rott A.S., Gessler C. \& Dorn S. 2010: Comparison between volatile emissions from transgenic apples and from two representative classically bred apple cultivars. - Transgenic Res. 19: 77-89.

WEI J.-N. \& KANG L. 2006: Electrophysiological and behavioral responses of a parasitic wasp to plant volatiles induced by two leaf miner species. - Chem. Senses 31: 467-477.

WINK M. 2006: Importance of plant secondary metabolites for protection against insects and microbial infections. In Carpinella C. \& Rai M. (eds): Naturally Occurring Bioactive Compounds. A New and Safe Alternative for Control of Pests and Diseases. 1st ed. Elsevier, Amsterdam, Boston, pp. 251-268.

Wu S.-B., Meyer R.S., Whitaker B.D., Litt A. \& Kennelly E.J. 2013: A new liquid chromatography-mass spectrometry-based strategy to integrate chemistry, morphology, and evolution of eggplant (Solanum) species. - J. Chromatogr. (A) 1314: 154-172.

ZhaNG H. 2017: Manipulation des végétaux par les organismes endophytes: Dialogue chimique et moléculaire entre les insectes manipulateurs de plantes et leurs plantes hôtes. $\mathrm{PhD}$ thesis, Université de Tours, 169 pp.

Zhang H., Dugé de Bernonville T., Body M., Glevarec G., Reichelt M., Unsicker S., Bruneau M., Renou J.-P., Huguet E., DubreuiL G. \& GIRON D. 2016: Leaf-mining by Phyllonorycter blancardella reprograms the host-leaf transcriptome to modulate phytohormones associated with nutrient mobilization and plant defense. - J. Insect Physiol. 84: 114-127.

Zhang H., Dubreuil G., Faivre N., Dobrev P., Kaiser W., Huguet E., VANKova R. \& GiRON D. 2018: Modulation of plant cytokinin levels in the Wolbachia-free leaf-mining species Phyllonorycter mespilella. — Entomol. Exp. Appl. 166: 428-438.

Received June 19, 2019; revised and accepted February 4, 2020 Published online February 24, 2020 
Table S1. Summary of average peak areas of all compounds detected by TD-GC-MS. The peak areas for the upper five compounds recorded in the mined, galled and control leaves were significantly different.

\begin{tabular}{|c|c|c|c|c|c|c|c|c|c|c|}
\hline \multirow{2}{*}{ No. } & \multirow{2}{*}{ Compound } & \multirow{2}{*}{$\begin{array}{c}\mathrm{RT} \\
(\mathrm{min}) \\
\end{array}$} & \multirow{2}{*}{$\begin{array}{c}\text { RI } \\
\text { Calculated }\end{array}$} & \multirow{2}{*}{$\begin{array}{c}\mathrm{RI} \\
\text { Literature } \\
\end{array}$} & \multicolumn{3}{|c|}{ Average peak area/cm² pre-treatment } & \multicolumn{3}{|c|}{ Average peak area/cm ${ }^{2}$ post-treatment } \\
\hline & & & & & Control & Mine & Gall & Control & Mine & Gall \\
\hline 1 & eucalyptol & 3.54 & 1228 & 1224 & n.d & 122.89 & 135.50 & 334.51 & 117.20 & 183.32 \\
\hline 8 & $\beta$-bourbonene ${ }^{a, e}$ & 5.21 & 1551 & 1585 & $7,874.61$ & $13,010.74$ & $23,486.71$ & $531,655.65$ & $519,375.10$ & $580,922.44$ \\
\hline 12 & unknown sesquiterpene 1 & 5.57 & 1616 & & $2,556.28$ & 530.03 & $3,701.44$ & $82,420.14$ & $55,520.19$ & $142,814.45$ \\
\hline 19 & farnesene ${ }^{\mathrm{a}, \mathrm{e}}$ & 6.36 & 1734 & 1725 & $22,451.98$ & $17,593.86$ & $94,646.76$ & $180,572.19$ & $282,557.57$ & $485,766.86$ \\
\hline 20 & unknown sesquiterpene 2 & 6.45 & 1746 & & $8,877.92$ & $5,185.83$ & $9,983.96$ & \multicolumn{3}{|c|}{$5,822,889.293,007,836.706,129,445.43$} \\
\hline 2 & $\beta$-ocimene ${ }^{a, e}$ & 3.72 & 1262 & 1242 & $68,086.71$ & $74,026.94$ & $123,691.60$ & $738,905.02$ & $522,452.55$ & $1,174,649.30$ \\
\hline 3 & unknown 1 & 4.00 & 1316 & & $164,666.05$ & $199,200.31$ & $232,291.61$ & $1,252,787.37$ & $616,764.72$ & $1,132,417.07$ \\
\hline 4 & unknown 2 & 4.03 & 1323 & & 927.79 & $3,093.55$ & 966.82 & $49,177.24$ & $24,691.47$ & $37,904.48$ \\
\hline 5 & $\alpha$-cubebene $b, e$ & 4.84 & 1481 & 1463 & $1,463.67$ & $1,909.40$ & $2,894.94$ & $168,011.03$ & $87,742.18$ & $144,193.40$ \\
\hline 6 & unknown sesquiterpene 3 & 4.90 & 1492 & & n.d & n.d & n.d & $28,641.48$ & $10,695.47$ & $50,728.89$ \\
\hline 7 & unknown sesquiterpene 4 & 5.06 & 1522 & & $6,484.39$ & $7,224.92$ & $9,012.21$ & $64,332.78$ & $43,496.04$ & $74,071.41$ \\
\hline 9 & unknown sesquiterpene 5 & 5.29 & 1566 & & $1,810.60$ & $1,923.21$ & $2,376.69$ & $123,875.62$ & $65,336.22$ & $141,246.44$ \\
\hline 10 & unknown sesquiterpene 6 & 5.39 & 1582 & & 108.57 & 207.07 & 83.72 & $167,858.45$ & $77,500.77$ & $89,115.24$ \\
\hline 11 & $\beta$-copaene & 5.54 & 1608 & 1585 & 591.82 & 739.87 & $1,307.94$ & $50,742.95$ & $31,583.64$ & $59,489.65$ \\
\hline 13 & unknown sesquiterpene 7 & 5.65 & 1627 & & $1,711.26$ & $2,494.76$ & $3,631.96$ & $126,217.45$ & $86,267.53$ & $158,447.42$ \\
\hline 14 & caryophyllene $e^{\mathrm{a}, \mathrm{e}}$ & 5.70 & 1633 & 1663 & $6,616.95$ & $6,255.08$ & $10,353.10$ & $270,435.20$ & $161,675.81$ & $234,033.88$ \\
\hline 15 & unknown sesquiterpene 8 & 5.78 & 1646 & & 664.19 & 512.77 & $1,656.93$ & $12,208.15$ & n.d & $1,904.07$ \\
\hline 16 & methyl benzoate ${ }^{\mathrm{d}, \mathrm{e}}$ & 5.82 & 1654 & 1635 & & & & 43, & $25,035.20$ & $25,294.26$ \\
\hline 17 & $\mathrm{y}$-muurolene ${ }^{\mathrm{b}, \mathrm{e}}$ & 6.17 & 1706 & 1684 & $7,100.86$ & $6,405.23$ & $10,511.43$ & $266,855.74$ & $170,196.22$ & $276,165.54$ \\
\hline 18 & unknown sesquiterpene 9 & 6.25 & 1718 & & $5,197.89$ & $5,813.73$ & $8,168.66$ & $149,050.59$ & $81,892.85$ & $195,811.66$ \\
\hline 21 & unknown sesquiterpene 10 & 6.54 & 1759 & & $315,081.33$ & $443,999.05$ & $693,291.04$ & $4,885,167.34$ & $4,490,019.77$ & $9,235,564.28$ \\
\hline 22 & unknown sesquiterpene 11 & 6.60 & 1767 & & $37,980.93$ & $45,833.13$ & $85,839.14$ & $87,804.25$ & $23,719.60$ & $91,854.49$ \\
\hline 23 & unknown sesquiterpene 12 & 6.71 & 1883 & & $21,656.28$ & $18,737.43$ & $26,252.05$ & $275,570.97$ & $146,826.73$ & $368,282.89$ \\
\hline 24 & unknown sesquiterpene 13 & 6.77 & 1890 & & $4,789.29$ & $5,275.57$ & $6,973.86$ & $191,513.83$ & $101,639.33$ & $243,827.39$ \\
\hline 25 & unknown 2 & 6.87 & 1904 & & $2,267.82$ & $8,850.39$ & $3,390.82$ & $274,229.28$ & $164,119.21$ & $229,489.54$ \\
\hline 26 & unknown sesquiterpene 14 & 6.93 & 1912 & & & & 737.39 & $37,762.47$ & $21,345.35$ & $51,132.15$ \\
\hline $27 \iota$ & unknown sesquiterpene 15 & 57.00 & 1921 & & $1,646.18$ & $1,524.32$ & $2,302.38$ & $51,844.16$ & $30,960.68$ & $79,152.65$ \\
\hline 28 & unknown 3 & 7.07 & 1931 & & 414.73 & $1,759.41$ & 874.36 & $61,301.49$ & $34,398.37$ & $49,912.74$ \\
\hline 29 & unknown 4 & 7.27 & 1956 & & 76.94 & 837.95 & 165.63 & $30,209.79$ & $17,033.54$ & $25,919.77$ \\
\hline $30 u$ & unknown sesquiterpene 16 & 7.34 & 1965 & & 152.87 & 81.23 & 118.58 & $39,980.28$ & $32,710.07$ & $81,837.98$ \\
\hline 31 & unknown 5 & 7.70 & 2008 & & 454.81 & 546.36 & $2,167.47$ & $24,118.19$ & $12,989.26$ & $17,277.92$ \\
\hline 32 & unknown 6 & 8.85 & 2025 & & $2,231.31$ & $2,920.67$ & $3,344.97$ & $46,871.55$ & $79,981.66$ & $80,426.60$ \\
\hline 33 & hexenol benzoate ${ }^{e}$ & 9.66 & 2079 & & $15,332.19$ & $19,677.09$ & $21,939.34$ & $59,442.48$ & $80,395.46$ & $95,819.47$ \\
\hline $34 u$ & unknown sesquiterpene 17 & 9.92 & 2095 & & $5,136.49$ & $5,087.44$ & $6,312.59$ & $8,422.44$ & $8,060.22$ & $15,927.51$ \\
\hline 35 & $\alpha$-cadinol b,e & 10.317 & 2119 & 2211 & $4,883.35$ & $4,602.08$ & $6,125.24$ & $11,919.25$ & $9,813.74$ & $21,308.71$ \\
\hline 36 & unknown 7 & 10.44 & 2126 & & n.d & n.d & n.d & $13,041.85$ & $8,827.29$ & $17,375.40$ \\
\hline
\end{tabular}

${ }^{a}$ Chung et al., 1993; b Choi, 2003; c Sylvestre et al., 2007; ${ }^{\text {d }}$ Ferreira et al., 2001; e NIST, 2011. 